\title{
BMJ Open Clinical specialty training in UK undergraduate medical schools: a retrospective observational study
}

\author{
Hrisheekesh J Vaidya, ${ }^{\oplus 1,2}$ Alexander W Emery, ${ }^{\circledR 2,3}$ Emma C Alexander, $^{\circledR 4}$ \\ Angus J McDonnell, ${ }^{1,5}$ Charlotte Burford, ${ }^{\oplus}{ }^{4}$ Max K Bulsara ${ }^{6}$
}

To cite: Vaidya HJ, Emery AW, Alexander EC, et al. Clinical specialty training in UK undergraduate medical schools: a retrospective observational study. BMJ Open 2019;9:e025403. doi:10.1136/ bmjopen-2018-025403

- Prepublication history and additional material for this paper are available online. To view please visit the journal (http:// dx.doi.org/10.1136/bmjopen2018-025403).

Received 14 July 2018 Revised 4 May 2019 Accepted 12 June 2019

A Check for updates

(c) Author(s) (or their employer(s)) 2019. Re-use permitted under CC BY-NC. No commercial re-use. See rights and permissions. Published by BMJ.

${ }^{1}$ Faculty of Medicine, Imperial College London, London, UK ${ }^{2}$ Medical Education, Medway NHS Foundation Trust, Gillingham, UK

${ }^{3}$ Keble College, University of Oxford, Oxford, UK

${ }^{4}$ Faculty of Life Sciences and

Medicine, King's College

London, London, UK

${ }^{5}$ Medical Education, East Kent Hospitals University NHS

Foundation Trust, Canterbury, UK

${ }^{6}$ Biostatistics, University of

Notre Dame, Fremantle, Western Australia, Australia

Correspondence to Dr Hrisheekesh J Vaidya; hjvaidya@gmail.com

\section{ABSTRACT}

Objectives To determine if increased exposure to clinical specialties at medical school is associated with increased interest in pursuing that specialty as a career after foundation training.

Design A retrospective observational study.

Setting 31 UK medical schools were asked how much time students spend in each of the clinical specialties. We excluded two schools that were solely Graduate Entry, and two schools were excluded for insufficient information.

Main outcome measures Time spent on clinical placement from UK undergraduate medical schools, and the training destinations of graduates from each school. A general linear model was used to analyse the relationship between the number of weeks spent in a specialty at medical school and the percentage of graduates from that medical school entering each of the Core Training (CT1)/Specialty Training (ST1) specialties directly after Foundation Year 2 (FY2).

Results Students spend a median of 85 weeks in clinical training. This includes a median of 28 weeks on medical firms, 15 weeks in surgical firms, and 8 weeks in general practice (GP). In general, the number of training posts available in a specialty was proportionate to the number of weeks spent in medical school, with some notable exceptions including GP. Importantly, we found that the number of weeks spent in a specialty at medical school did not predict the percentage of graduates of that school training in that specialty at CT1/ST1 level ( $B$ coefficient $=0.061, p=0.228$ ).

Conclusions This study found that there was no correlation between the percentage of FY2 doctors appointed directly to a CT1/ST1 specialty and the length of time that they would have spent in those specialties at medical school. This suggests that curriculum adjustments focusing solely on length of time spent in a specialty in medical school would be unlikely to solve recruitment gaps in individual specialties.

\section{INTRODUCTION}

The National Health Service is facing unprecedented recruitment pressures, particularly in areas such as general practice (GP). In 2015, the Department of Health set a specified target to recruit an extra 5000 GPs by $2020 .{ }^{1}$ However, there are concerns this target may not be met. ${ }^{2}$ Other areas are also facing pressures, notably

\section{Strengths and limitations of this study}

- This study synthesises a large dataset on the amount of time spent in clinical specialties for students in 27 of the 29 UK undergraduate medical schools, using a novel and reproducible method of data collection (freedom of information requests) to demonstrate a marked heterogeneity among UK medical school curricula.

- Rather than relying on subjective metrics such as questionnaires to determine what motivated junior doctor career decisions, we looked at actual successful career training allocations for 2672 doctors, and used an objective metric (the time schools allocate to specialities) to examine the role specialty exposure plays in career decision making for all clinical specialties available at Core Training (CT1)/ Specialty Training (ST1) level.

- Among the limitations, this study collected data on curricula and of the specialty decisions of doctors entering CT1/ST1 in 2016, although these doctors would have completed medical school in 2014. The 2014 curricula that these doctors were exposed to may have been different from the 2016 curricula that we obtained information on.

- This study only considered graduates who entered CT1/ST1 directly after FY2, and therefore there is missing data for approximately half of all doctors; the factors influencing these doctors on specialty decisions may differ significantly. We also do not have data on which specialty doctors applied to for their CT1/ST1 jobs, only the specialty they obtained a job in.

- The impact of student-selected components or assistantships, and any exposure to specialties during the 'preclinical' portion of medical teaching, could not be assessed, although the weeks spent in these placements may influence career choice.

psychiatry and emergency medicine. ${ }^{3}$ It has been suggested that increasing exposure to these specialties at medical school may help increase recruitment. ${ }^{4-9}$ We wished to investigate this hypothesis.

After medical school, doctors in the UK enter a 2-year Foundation programme 
(FY1, FY2), the completion of which allows entry into a specialty training programme after a competitive application process. Approximately half of FY2 doctors progress directly into these training programmes, while the other half take time out or do not continue postgraduate training. Further specialty training takes the form of Core Training (CT1) or Specialty Training (ST1) programmes. Core training programmes are generally 2 years long, and trainees then progress into specialty training programmes (ST3), whereas specialty training programmes run straight through from ST1 to completion of training.

Several factors may influence the specialty that doctors choose to enter, including personality traits, perceptions of the work-life balance, length of training and quality of placements during medical school. ${ }^{10}$ These have generally been studied through questionnaires of medical students or junior doctors. Outside of the UK, studied approaches to increase recruitment to hard-to-recruit specialities or rural areas have included placing students local to home, early sign-ups for medical internships and mentoring, ${ }^{4-6}$ with some studies suggesting that positive rural placements lead to increased interest in rural practice. ${ }^{78}$ Within the UK, it has also been suggested that length of exposure to a medical specialty at medical school influences career choice..$^{911-15}$ Based on this, it is argued that medical school curricula should be more appropriately tailored to the recruitment demands of the 21st century.

Recent research appears to have identified an association between the quantity of clinical GP teaching at medical school and entry into UK GP training; Alberti ${ }^{9}$ found that there was a statistically significant association between the quantity of clinical GP training and the percentage of graduates entering the GP training pathway directly after FY2. ${ }^{9}$ However other specialties have not, to our knowledge, been examined in the same way. The majority of other evidence supporting the suggestion that exposure determines later choices comes from surveys conducted during medical school, where students are asked either about their interest in pursuing a specialty after having been exposed to that specialty on placement, ${ }^{11} 1415$ or about their perceptions or attitude to that specialty as a whole. ${ }^{16}$ However, preferences at this point may be transient ${ }^{17}$ and so not actually have an impact on future career decisions. Furthermore, historical trends do not appear to show that progressive increases in exposure to general practice over the last 30 years ${ }^{6}$ have correlated with an increase in the proportion of UK graduates entering GP. ${ }^{18}$

In the UK, the General Medical Council supports and regulates medical education, and is responsible for quality assurance. Medical schools are free to design their own curricula, and guidance prior to $2016^{19}$ stated that these curricula must be structured to include a range of specialties, 'including medicine, obstetrics and gynaecology, paediatrics, surgery, psychiatry and GP'. However, since January 2016, when Tomorrow's Doctors ${ }^{19}$ was superseded by Promoting excellence, ${ }^{20}$ the guidance on the clinical specialties that students must be exposed to has become more generalised-now simply stating that 'medical school curricula must give medical students experience in a range of specialties, in different settings, with the diversity of patient groups that they would see when working as a doctor (R5.3b).'

We wanted to understand the current exposure to different medical specialties at UK undergraduate medical schools and examine how this compared with the number of posts available at CT1/ST1. We also wanted to examine the relationship between exposure to clinical specialties at medical school and the percentage of each school's graduates being appointed to each postgraduate CT1/ST1 specialty training programme directly after FY2.

\section{METHODS}

\section{Data collection}

Freedom of Information (FOI) requests were sent to all 29 UK undergraduate medical schools asking how much time students spend on placement in each of the medical specialties as part of their clinical education. We excluded schools that were solely Graduate Entry due to differences in the structure of their curricula, and we also excluded recently established schools who had not yet produced medical graduates. Where data were missing, or medical schools did not respond, we accessed university websites (March 2017) to obtain as complete a dataset as possible.

An additional FOI request was sent to Health Education England (HEE) to determine the medical school attended by each doctor entering a specialty training programme immediately after foundation training in 2016. This used the self-declared appointments of FY2 doctors completing the mandatory National F2 Career Destination Survey 2016. Approximately half of these doctors did not enter any specialty training programme at this point. We received permission from HEE to publish the data in a journal.

Finally, we accessed publicly available data on 2016 specialty training posts and applications from the HEE website.

\section{Patient and public involvement}

There was no patient or public involvement in this study.

\section{Data cleaning}

Data were collated into a spreadsheet and analysed with Microsoft Excel 2016, SPSS V.24.0, and SciPy (Scipy V.0.19.1, Python V.3.6.0).

Any medical schools for which we could only classify a number of weeks less than one IQR below the lower quartile (Q1-IQR) were excluded due to insufficient data.

The names and scope of individual curricula components differed between medical schools. We therefore standardised the curricula based on the training programmes offered by HEE so that appropriate curriculum components were linked with their relevant CT1/ ST1 specialty (online appendix table A1). As very few medical schools offered cardiothoracic surgery, maxillofacial surgery or neurosurgery specifically, and all three are available at both ST1 and ST3 level, we combined these into surgery. 


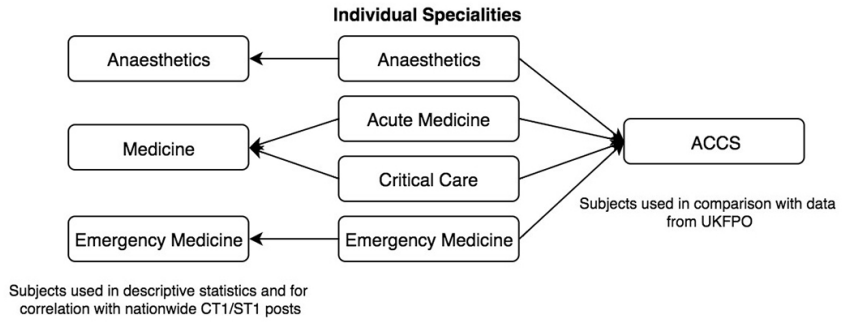

Figure 1 Sorting of ACCS Specialities according to individual analyses. ACCS, Acute Care Common Stem.

Special attention is drawn to the components of the Acute Care Common Stem (ACCS) programme: Emergency Medicine, Anaesthetics, Critical Care, Acute Medicine. The latter two of these were combined into Medicine for the first part of the analysis, as this is how HEE group the subjects. However, for the final part of our analysis, specialty information from the survey carried out by the UK Foundation Programme Office (UKFPO) was provided with data grouped as 'ACCS' and 'Anaesthetics'. We collated both into a single 'ACCS' specialty, and compared this with a composite category from our curricula data with all four ACCS components (figure 1).

\section{Statistical models}

A Shapiro-Wilk test for normality was performed using SPSS V.24.0 to determine appropriate descriptive statistics to describe our data. The Shapiro-Wilk test for normality revealed that data for two specialties, ACCS and ophthalmology, were non-normally distributed, so the median was used to describe all data.

A general linear model was used to analyse the relationship between the number of weeks spent in a specialty at medical school and the percentage of FY2 graduates from that medical school entering each of the GT1/ST1 specialties.

\section{RESULTS}

\section{Current clinical curricula at UK undergraduate medical}

\section{schools}

Our FOI requests gathered responses that detailed placement time for all clinical years from 24 of the 29 established undergraduate medical schools in the UK. Three of the five remaining schools had sufficiently detailed information on their websites for our analysis. The remaining two medical schools were excluded due to insufficient data, leaving 27 medical schools in our analysis.

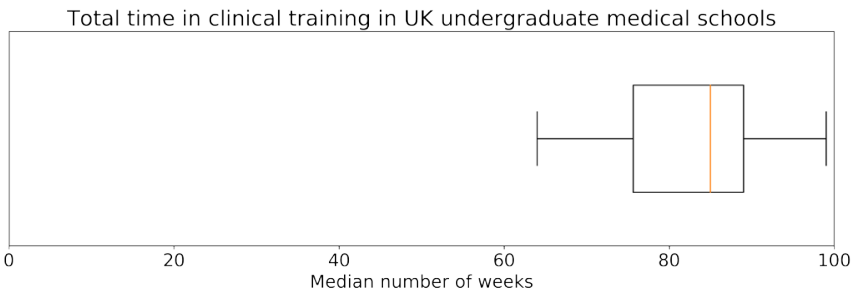

Figure 2 Total time in clinical training in UK undergraduate medical schools.

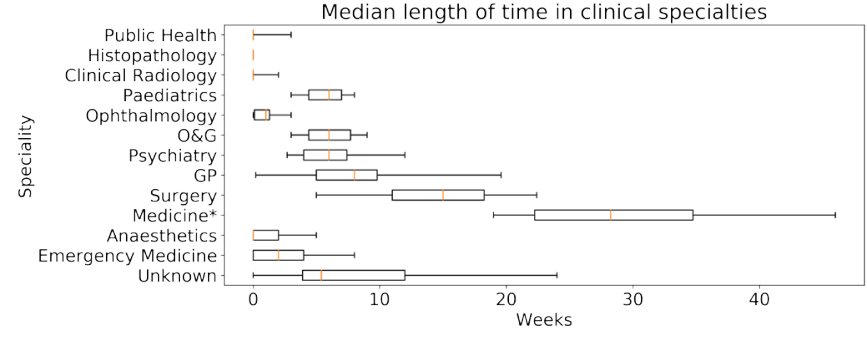

Figure 3 Box plots showing median length of time spent at medical school in different clinical specialities, with whiskers showing range. *Medicine includes acute medicine and critical care. GP, general practice; O\&G, obstetrics \& gynaecology.

UK medical students spend a median of 85 weeks in clinical training, with a wide variation between medical schools (range 64-99, figure 2).

During this time, a median of 28 (IQR 22-35) weeks is spent in medical specialties, 15 (IQR 11-18) weeks in surgical specialties and 8 (IQR 5-10) weeks in GP (figure 3). The remaining time is spent on obstetrics and gynaecology, paediatrics and psychiatry (6weeks each), ophthalmology (1 week; figure 3 ) and other specialties.

Notably, most medical schools had several weeks that could not be classified, as the information provided by the medical school was unclear, or it varied between students, such as in student-selected components (also known as 'special study modules') or FY1 shadowing/student assistantships. Medical schools had a median of 5.2 weeks in this 'Unknown' category.

From the available data it appeared that some specialties lacked dedicated time within the curricula of most medical schools. Notably, of 27 schools, only 10 reported dedicated time in anaesthetics, only six for public health and three for clinical radiology. None of the medical schools allocated any clinical time specifically to histopathology that was labelled as such.

\section{Median medical school exposure and number of CT1/ST1 training posts and applications}

We first examined the median exposure to a specialty across all medical schools, and compared this with the total nationwide number of training posts available in that specialty at CT1/ST1 level (figure 4). Excluding GP, there is a statistically significant positive relationship between the median length of time spent in a specialty at medical school and the number of training posts available in that specialty at CT1/ST1 level (when excluding $\mathrm{GP}$, correlation $=0.91, \mathrm{p}<0.001$ ). GP is notable for having a much higher proportion of jobs available (3802 posts, $43 \%$ of all CT1/ST1 jobs) compared with the number of weeks spent on clinical attachment at medical school (median 8 weeks; less than $10 \%$ of time in the clinical years of medical school). To better visualise specialties that were comparatively over-represented or under-represented at medical school, we have plotted a line of best fit for all hospital specialties (ie, excluding GP). 


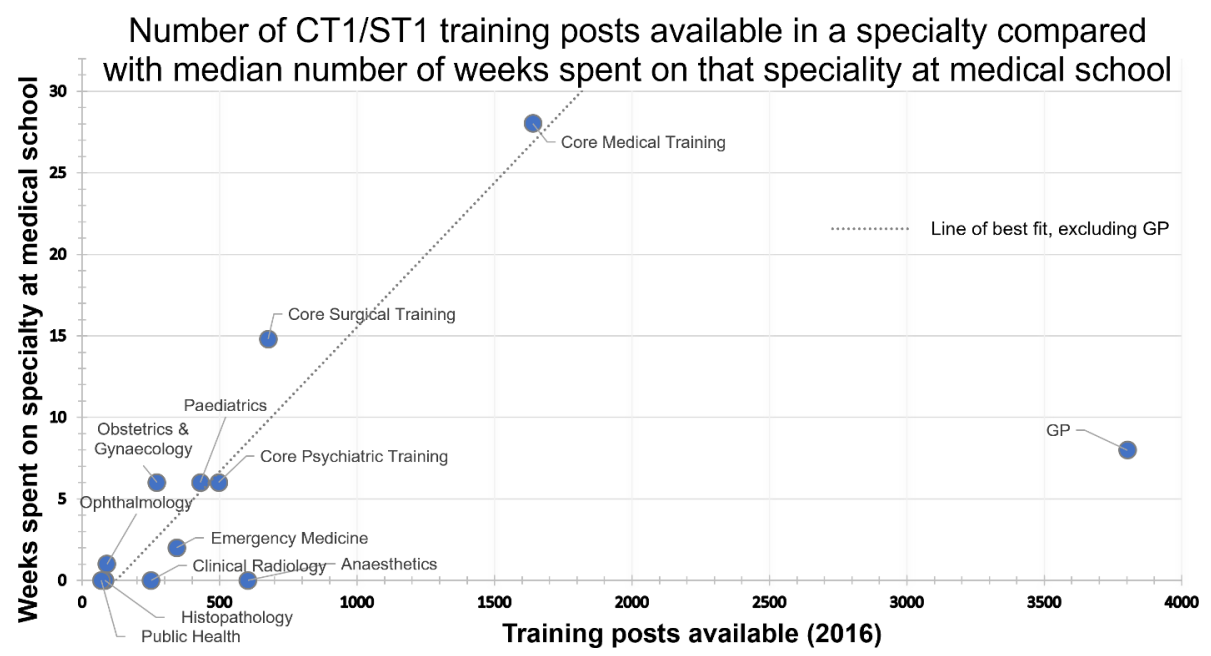

Figure 4 Scatter plot comparing CT1/ST1 posts available for a specialty and the median number of weeks spent on that specialty at medical school. Line of best fit drawn using all hospital specialties; that is, excluding GP. CT1, Core Training; GP, general practice; ST1,Specialty Training. .

We found similar results when we considered median medical school exposure and the total number of applications to CT1/ST1 posts (online appendix figure 1).

\section{Medical school exposure and number of alumni entering CT1/} ST1 specialty training after FY2

The data obtained from HEE included 6752 respondents from 34 UK medical schools and categories for non-UK European Economic Area and non-European Economic Area schools. Of these, 3231 doctors $(47.85 \%)$ reported that their next destination was specialty training in the UK. Non-UK and graduate medical schools were excluded, as were those responses that were left blank. This left 2672 responses. These results were normalised with the total number of respondents as the denominator, to give the percentage of respondents from each included medical school that picked a particular specialty (including GP). This was then compared with the number of weeks that students from that medical school spend on that specialty.

A generalised linear model was fitted to investigate the relationship between medical school exposure and number of alumni entering specialty training. The dependent variable was the percentage of graduates from each medical school who entered a specialty after FY2, and the independent variables were the number of weeks during medical school spent on that specialty, the specialty, and the medical school. Our model shows the number of weeks of training does not have any impact on the percentage of alumni choosing the specialty ( $\beta$ coefficient $=0.061, \mathrm{p}=0.228$ ).

A scatter plot (figure 5) visualises this this relationship. Overall, there is a clear correlation between the number of weeks spent on a specialty and the percentage of doctors picking that specialty after FY2: medical students spend more weeks in specialties that have more jobs. However, looking at any individual specialty, there is no association; that is, changing the number of weeks spent on a specialty between medical schools has no impact on the percentage of FY2 doctors entering that specialty.

\section{DISCUSSION}

We found that the clinical curriculum in medical schools across the country varies widely, both in the total number of weeks spent in clinical education, and in how this time was divided among different clinical specialties. This division of time in medical school is generally proportional with the number of posts available at CT1/ST1 level,

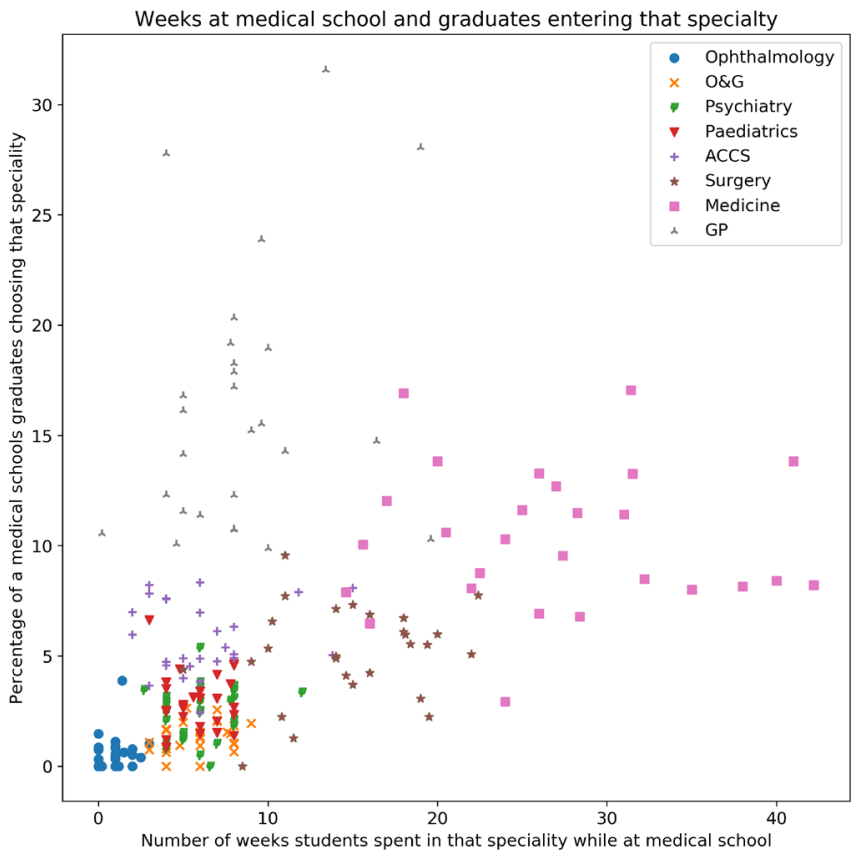

Figure 5 Scatter plot comparing number of weeks spent in a specialty at medical school, with the percentage of graduates from that medical school who entered that specialty after FY2. ACCS, Acute Care Common Stem; GP, general practice; O\&G, obstetrics \& gynaecology. 
with the notable exception of GP. However, we found no evidence that spending more weeks on a specialty placement at medical school had any effect on a students' likelihood of entering that subject at CT1/ST1 level.

Compared with the percentage of CT1/ST1 jobs available, students spent a disproportionately long time in medical school on obstetrics \& gynaecology and surgical specialties. Conversely, GP was under-represented, with students spending a median of 8 weeks $(9 \%)$ on GP placements, even though over $40 \%$ of CT1/ST1 posts were in GP. Similarly, students spent less time in the ACCS specialties than the number of CT1 jobs would imply is appropriate, and 17 schools did not report any formal time in anaesthetics.

We also found that most medical schools did not allocate and label any specific clinical time on radiology, histopathology or public health. It may be argued that much of the content of these specialties is covered in preclinical and extraclinical education, and some specialties have greater crossover than others-for example, radiology is interwoven into most other specialties; positive exposure to obstetrics could make a student more sympathetic to surgery in general; end of life experiences across all specialties could encourage an interest in palliative medicine. Similarly, the lower amount of time spent on GP placement may simply be because many of the diseases and treatments experienced in GP are also encountered across the various hospital specialties.

However, their exclusion may force many doctors to seek exposure during taster weeks in the foundation years if they wish to experience the day-to-day life of doctors in these specialties. This is significant as data from UKFPO (2016) show that $62 \%$ of doctors do not change their first preference of specialty training programme over the course of their Foundation years. ${ }^{21}$ Of those that do, $19.7 \%$ preferred a different specialty, rather than being deterred from their original choice due to a negative rotation $(3 \%)$ or due to a change in personal circumstances $(7.8 \%) .{ }^{21}$ Additionally, some competitive specialties such as neurosurgery usually require a rich $\mathrm{CV}$ with multiple publications in order to secure a training number, which may be hampered by insufficient exposure during medical school. Overall, however, our data suggest that relative exclusion or overemphasis of specialties does not appear to affect career decisions. This is contrary to previous studies that used survey responses after medical school placements. ${ }^{1114-16}$

Our results also differ from a study conducted by Alberti $e t$ al using data from doctors starting GP training in 2014 and 2015, which had reported a significant association between the quantity of 'authentic' GP teaching in medical school (defined as teaching in a practice with patient contact) and the percentage of graduates entering GP training ${ }^{9}$ directly after FY2. We looked at all specialty training programmes, including GP training, and found no association. This difference may be explained by a number of factors. First, a statistically significant association (defined without correction for multiple analyses at $\mathrm{P}=0.05$ ) was only found in the subgroup analysis for 'authentic GP teaching' whereas our analysis may have also captured non-clinical specialty exposure during clinical years, for example through small group teaching. Second, the observed association was weak; Alberti reported correlation coefficients of 0.41 and 0.3 for 2014 and 2015 respectively.

This result does not exclude the possibility that time spent on specialty rotations does affect career preference, rather that whatever that effect may be did not translate to a measurable change in specialty training choice in our study. Any effect may also be masked by other factors. For example, some students may be dissuaded from doing a specialty after placement time, or doing a placement may encourage students to choose a specialty, but in a non-linear way - such that doing 10 weeks may be no more influential than doing 1 week. As reported in Burford et $a l$ when investigating student interest in the brain-related specialties, factors such as a negative experience on placement were self-reported as deterrents, but additional factors such as positive experiences during intercalated degrees may be influential. ${ }^{22}$

We believe our study is the first to consider actual career destinations of all UK CT1/ST1 doctors in a single year group cohort and attempt to correspond these with the clinical curricula of their medical school. We acquired unpublished data directly from nearly all medical schools in the UK from HEE, and hope this resource may be helpful for educators and students.

There were several limitations in our methodology. First, we looked at 2016/17 data for the medical school curricula, and 2016 data for CT1/ST1 jobs. However, doctors applying in the 2016 cycle would have completed medical school in 2014. The curricula at their medical school may have changed in that time.

Second, we looked at just 1 year's worth of data, while the number of doctors entering each training programme changes year-on-year. However, this year-on-year variation is small relative to the differences between specialties (online appendix figure 2).

Furthermore since our data were from UKFPO's report on destinations after FY2, we only have information on doctors who are directly progressing to ST1/CT1 immediately after FY2. We do not have information on the specialties chosen by the $50.4 \%$ of doctors who did not directly enter specialty training after FY2. These graduates may disproportionately be those attempting to enter competitive specialties, or doctors who are still undecided between multiple specialties, and therefore the specialty decisions of these doctors remain unknown.

Thirdly, it is possible that some exposure to certain specialities was not captured by our study. Every medical school we studied had some time allocated for student-selected components (special study modules), or assistantships. The specialties involved in these components of clinical courses would vary from student to student, and so we could not categorically allocate it to any individual specialty. A median of 5.2 weeks (IQR 3.6-12) is spent on this 'Unknown' category, and for some students this will have included specialties we thought were under-represented or over-represented. Indeed, student-selected 
components are frequently chosen in the specialties students most think they wish to do in the future, and therefore this 'Unknown' may hide the most formative weeks in a student's clinical education.

In addition, it should be mentioned that some medical schools are moving towards earlier clinical contact even from the first year. This is particularly the case for GP where some schools conduct visits once a week during the traditionally 'preclinical' years. Depending on how universities interpreted our request, such exposure could have been missed.

Finally, we do not have a breakdown of which specialty each doctor applied to for their CT1/ST1 job based on their medical schools. The application process is competitive, so even if spending longer on a placement increased an applicant's desire to enter a specialty, this may not show itself in the numbers of candidates who were successful. We do note however that on a nationwide scale, the specialties that that are oversubscribed at CT1/ST1 level are not those that are over-represented in medical school. ${ }^{21}$

\section{CONCLUSION}

UK medical school curricula are heterogeneous, with different universities allocating often vastly different amounts of time to different specialties. Across the UK as a whole, the amount of time spent in medical school on a specialty is approximately proportional with number of specialty training posts available in that specialty, with notable exceptions including GP. However, analyses from our study have suggested that the amount of time spent in different specialties at medical school does not impact on the likelihood of graduates from that medical school entering that specialty directly after completion of foundation training.

Our findings challenge the perception that increasing specialty exposure enhances recruitment and suggest that curriculum adjustments focusing solely on length of time in certain settings will not resolve recruitment gaps going forward.

Contributors HJV, AWE and AJM conceived of the study and its design. ECA and AWE completed initial data collection and HJV, AWE and AJM completed data extraction. MKB and HJV completed the statistical analysis and CB assisted. HJV and AWE wrote the majority of the first draft, and the other authors contributed to refine it. All authors then contributed to refine and review the final draft and gave their consent for submission. HJV serves as the guarantor for this piece.

Funding The authors have not declared a specific grant for this research from any funding agency in the public, commercial or not-for-profit sectors.

Competing interests None declared.

Patient consent for publication Not required.

Provenance and peer review Not commissioned; externally peer reviewed.

Data sharing statement Raw data used to complete this study is available from the authors on request.
Open access This is an open access article distributed in accordance with the Creative Commons Attribution Non Commercial (CC BY-NC 4.0) license, which permits others to distribute, remix, adapt, build upon this work non-commercially, and license their derivative works on different terms, provided the original work is properly cited, appropriate credit is given, any changes made indicated, and the use is non-commercial. See: http://creativecommons.org/licenses/by-nc/4.0/.

\section{REFERENCES}

1. NHS England. General Practice: Forward View. 2016. https://www. england.nhs.uk/wp-content/uploads/2016/04/gpfv.pdf (accessed 16 Nov 2018).

2. Kaffash J. Will the NHS deliver 5,000 extra GPs by 2020? Pulse, 2017.

3. NHS England. Five year forward view, 2014.

4. Landry M, Schofield A, Bordage R, et al. Improving the recruitment and retention of doctors by training medical students locally. Med Educ 2011:45:1121-9.

5. Gaski M, Abelsen B. Designing medical internships to improve recruitment and retention of doctors in rural areas. Int $J$ Circumpolar Health 2017;76:1314415.

6. Torrible SJ, Diachun LL, Rolfson DB, et al. Improving recruitment into geriatric medicine in Canada: Findings and recommendations from the geriatric recruitment issues study. J Am Geriatr Soc 2006;54:1453-62.

7. Ray RA, Young L, Lindsay D. Shaping medical student's understanding of and approach to rural practice through the undergraduate years: a longitudinal study. BMC Med Educ 2018;18:147.

8. Curran V, Rourke J. The role of medical education in the recruitment and retention of rural physicians. Med Teach 2004;26:265-72.

9. Alberti $\mathrm{H}$, Randles HL, Harding A, et al. Exposure of undergraduates to authentic GP teaching and subsequent entry to GP training: a quantitative study of UK medical schools. Br J Gen Pract 2017;67:e248-e252.

10. Spooner S, Pearson E, Gibson J, et al. How do workplaces, working practices and colleagues affect UK doctors' career decisions? A qualitative study of junior doctors' career decision making in the UK. BMJ Open 2017;7:e018462.

11. Howe A, Ives G. Does community-based experience alter career preference? New evidence from a prospective longitudinal cohort study of undergraduate medical students. Med Educ 2001;35:391-7.

12. Harding A, Rosenthal J, Al-Seaidy M, et al. Provision of medical student teaching in UK general practices: a cross-sectional questionnaire study. Br J Gen Pract 2015;65:e409-e417.

13. Nicholson S, Hastings AM, McKinley RK. Influences on students' career decisions concerning general practice: a focus group study. Br J Gen Pract 2016;66:e768-e775.

14. Ibrahim M, Fanshawe A, Patel V, et al. What factors influence British medical students' career intentions? Med Teach 2014;36:1064-72.

15. Cleland JA, Johnston PW, Anthony M, et al. A survey of factors influencing career preference in new-entrant and exiting medical students from four UK medical schools. BMC Med Educ 2014;14:151.

16. Adekunte O, Owen B, Oliver C. Before and after: Effect of 4-week psychiatry attachment on medical students' attitude to psychiatry as a career choice. European Psychiatry 2016;33:S434.

17. Morrison JM, Murray TS. Career preferences of medical students: influence of a new four-week attachment in general practice. $\mathrm{Br} \mathrm{J}$ Gen Pract 1996;46:721-5.

18. Lambert TW, Evans J, Goldacre MJ. Recruitment of UK-trained doctors into general practice: findings from national cohort studies. Br J Gen Pract 2002;52:364-72.

19. General Medical Council. Tomorrow's Doctors. 2009. https://www. gmc-uk.org/education/standards-guidance-and-curricula/standardsand-outcomes/outcomes-for-graduates (accessed 17 Nov 2018).

20. General Medical Council. Promoting excellence: standards for medical education and training. 2015. https://www.gmc-uk.org/ education/standards-guidance-and-curricula/standards-andoutcomes/promoting-excellence (accessed 17 Nov 2018).

21. The Foundation Programme. Career Destination Report 2016. 2016.

22. Burford C, Alexander E, Sloper W, et al. Factors influencing interest in the brain-related sciences in a UK cohort. J Neurol Sci 2017;377:77-8. 